\title{
UNIVERSITYOF
}

FORWARD

THINKING

WESTMINSTER用

WestminsterResearch

http://www.westminster.ac.uk/westminsterresearch

Entity Regulation, Litigation Rights and the Changing Meaning of

Professionalism at the Bar of England and Wales

Mason, M.

This is an accepted manuscript of an article published by Taylor \& Francis in Legal

Ethics, DOI: 10.1080/1460728x.2020.1833130.

The final definitive version is available online:

https://doi.org/10.1080/1460728x.2020.1833130

(C) 2020 Taylor \& Francis

The WestminsterResearch online digital archive at the University of Westminster aims to make the research output of the University available to a wider audience. Copyright and Moral Rights remain with the authors and/or copyright owners. 


\section{Entity Regulation, Litigation Rights and the Changing Meaning of Professionalism at the Bar of England and Wales}

Marc Mason*

Senior Lecturer, Centre on the Legal Profession, Westminster Law School, University of Westminster

m.mason@westminster.ac.uk

https://orcid.org/0000-0002-6199-9060

* The author would like to gratefully acknowledge the extensive guidance, support and encouragement from Lisa Webley throughout the development of this article, and the helpful comments of the two anonymous reviewers. 


\title{
Entity Regulation, Litigation Rights and the Changing Meaning of Professionalism at the Bar of England and Wales
}

\begin{abstract}
The Legal Services Act 2007 provided a framework for a liberalised marketplace for legal services. The most significant responses to this by the Bar appear in the Bar Standards Board Handbook, which was first released in January 2014. This included changes allowing for barristers to engage in litigation and enabling the Bar Standards Board to regulate entities rather than just individual barristers. This article places these changes within the existing theoretical understanding of the legal professions and professionalism, and argues that they open the door for a significant shift in the way that the discourse of professionalism is used in relation to the Bar.
\end{abstract}

The Bar Standards Board (BSB) released its new format of the Handbook in January 2014. This was a substantial rewriting of the rules and principles governing the Bar. A major impetus for those changes appears to be the need to comply with the recommendations of the Clementi Report and to implement a substantial new regime for regulating Alternative Business Structures. The Handbook has provided an opportunity for the BSB to significantly alter the way the profession is both defined and governed. These alterations include an increased regulation of unregistered barristers, ${ }^{1}$ the option for litigation rights (rights to prepare cases for filing, usually the preserve of solicitors), a duty to report the misconduct of other barristers, changes to responsibility for chambers management, and outcomes focused and risk-based regulation. ${ }^{2}$ This article will look at the rules, guidance and consultations relating to two of these changes: entity regulation and litigation rights, in order to argue that the changes are

\footnotetext{
${ }^{1}$ Marc Mason, 'UK: Room at the Inns - The Increased Scope of Regulation under the new Bar Standards Board Handbook for England and Wales' (2014) 17(1) Legal Ethics 143

${ }^{2}$ Marc Mason, 'Making Way for Change at the Bar: The Practical Implications of the new Bar Standards Board Handbook' (2015) 31(3) Journal of Professional Negligence 139
} 
aligned with broader neoliberal ${ }^{3}$ tendencies and represent a critical moment in a shift from occupational to organizational professionalism. It will further argue that the BSB appears to be positioning itself to make the most of the emerging regulatory market place in light of such changes, to become the regulator of choice for legal professionals engaged in a broader range of legal work that would hitherto be associated with the Bar.

By way of introduction it may be of assistance to examine key competing theories of the legal professions (or indeed of professions more generally) to provide a foundation for understanding regulatory approaches. Closure, or conflict, theories as exemplified by Abel, 'focus on the nature and extent of occupational control over the supply of services' ${ }^{4}$ and essentially look at how professions gain legitimacy and use this legitimacy to control the market for services to

${ }^{3}$ Neoliberalism generally refers to the dynamic process of political, economic and social restructuring that emphasizes the market as the most appropriate and efficient institution for regulating social order and thus brings all human action within the domain of the market. As Webley (2015) points out "its Anglo-American, post-welfare, capitalist, right-leaning roots have dominated the intellectual realm where the market is deemed to be a neutral force for individual freedom and prosperity" (at p 2353). Baron (2014) points to a resultant wave of deregulation, privatisation, and the withdrawal of the state from areas of social provision internationally since the 1970s aided by the positioning and dominance of its apologists across a wide range of positions of policy influence, leading to a striking reshaping of 'common sense.' It is criticised as incorporating authoritarian and imperialistic tendencies, entrenching corporate freedoms at the cost of human freedom, and as overemphasizing individual responsibility whilst devaluing the importance of collective ideals and the democratic state. See Simon Springer, Kean Birch and Julie MacLeavy (eds), The Handbook of Neoliberalism (Routledge 2016); Lisa Webley, 'Legal Professional De(re)regulation, Equality, and Inclusion, and the Contested Space of Professionalism within the Legal Market in England and Wales' (2015) 83 Fordham Law Review 2349; Paula Baron 'Sleight of Hand: Lawyer Distress and the Attribution of Responsibility' (2014) 23(2) Griffith Law Review 261; Simon Springer, Kean Birch and Julie MacLeavy (eds), Handbook of Neoliberalism (Routledge 2016).

${ }^{4}$ Richard L Abel, The Legal Profession in England and Wales (Basil Blackwell 1988), 19 
their own ends. This group of theories looks at how adversaries within classes compete within the marketplace, how they jostle for superior position, deploying strategies of social closure, closing off areas of work to outsiders through reserving activities for nominated professionals, and internally controlling that work. ${ }^{5}$ On this view the professional project sets out to control the market and improve the status of the profession. This is done through a process of first controlling production of producers, or controlling entry (formally through stated entry requirements or informally for example through conditions that require a financial commitment such as insecure income in early years), then by controlling production by producers. The former provides an obvious mechanism for increasing income by reducing competition via a quasi-number cap on professionals who may compete with each other. It also serves to act as a control on the way the profession is perceived, through delineating the characteristics required of individuals to be admitted to the profession, and thus seeks to control the status of the profession. The latter similarly has a dual purpose of both limiting internal and external competition and enhancing status. One of the particular strengths of closure theories has been the extent to which they have acted as a counterbalance to functionalist theories which had been the dominant framework through which the professional framework had been constructed.

For structural functionalist theorists, notably Parsons, the professions have been seen as a benevolent 'antidote to the insidious poison of selfish materialism', essentially framing professionalism as a counterbalance to the aims and needs of individual lawyers, and a way of working towards more socially useful and worthy ambitions through a professional project. In essence, professional organisation has been viewed through a vocational lens with a unifying project being worked on by all within the profession. The influence of these functionalist

\footnotetext{
${ }^{5}$ Ibid, 4-5

${ }^{6}$ Ibid, 5
} 
approaches, and particularly their trait based nature can perhaps be seen in the Royal Commission on Legal Services defining what it considered to be the five main features of a profession: a governing body with powers over members, a specialised field of knowledge, control of admission through tests of competence, self regulation (leading to higher standards), and overriding responsibility to the client. ${ }^{7}$ Control by the profession is in service of the client and the rule of law rather than the profitability of individual professionals and the means by which they compete for business.

The traits set out by the Royal Commission are discernible as clauses in neo-contractual theory, which could be said to be the more recent adopter of at least some elements of functionalist theory. ${ }^{8}$ Paterson describes professions, under this theoretical framework, as a combination of attributes orientated towards others and attributes which are self-orientated, to form a contract where the profession offers social goods such as access and a service ethos, but also has a corresponding and reciprocal interest in its own benefits such as status, rewards and autonomy. From time to time this contract gets renegotiated, but in periods of stability it becomes viewed as tradition. ${ }^{9}$ In this way these more current interpretations avoid the static nature both of the structural functional approach and the trait based approach. Paterson views this as a healthy and normal feature of professions, and one that the professions have to wrestle with. As a result he also sees benefit in a professional body that combines regulatory and representative functions, where both sides of the contract have to be examined and balanced by one body, producing a tension which leads to a healthy dialogue. ${ }^{10}$

Whilst these theories pay close attention to the internal workings and motivations of the

\footnotetext{
${ }^{7}$ Royal Commission on Legal Services, Final Report, (HMSO 1979) as cited in Abel (n 3), 6-7

8 Alan Paterson, Lawyers and the Public Good (2012 Cambridge University Press)

${ }^{9}$ Ibid, $14-15$

${ }^{10}$ Ibid, 33
} 
professions more recent research has focused on the broader setting in which the professions operate, and the discourse in which professionalism is located and created. Evetts ${ }^{11}$ in particular shifts the emphasis onto professionalism as a discourse, highlighting a key distinction as that between occupational professionalism and organizational professionalism. Taking this focus Evetts examines how the discourse of professionalism facilitates change and control of an occupation. This discourse can be deployed from within, as in occupational professionalism, or from 'above' as in organizational professionalism. Occupational professionalism represents the traditional discourse, particularly in professions such as law and medicine, whilst organizational professionalism can be discerned as an emerging form tied to a more managerial discourse. The former carries with it ideas of collegiality and trust in an individual practitioner, the latter carries ideas of standardization, quality control and hierarchy.

Webley ${ }^{12}$ has charted a shift in discourse and reforms of the legal professions in England and Wales, noting a move to neoliberalism with desacralization and depoliticization, an emphasis on private solutions and consumer power and reification of the market as a 'common sense totalizing force for good. ${ }^{13}$ Sommerlad describes how through a managerial ideology, in which efficiency is prioritised and quality is relativized to gain meaning from only the consumer viewpoint then 'in the name of the defence and 'empowerment' of the consumer, this entrepreneurial, minimal state has... violated the integrity of that part of the profession

\footnotetext{
${ }^{11}$ Julia Evetts, 'Short Note: The Sociology of Professional Groups New Directions Professions: A More Pragmatic Approach to Defining the Field CS' (2006) 54 Current Sociology 133; Julia Evetts, ‘A New Professionalism? Challenges and Opportunities' (2011) 59 Current Sociology 406.

${ }^{12}$ Lisa Webley, 'Legal Professional De(re)regulation, Equality, and Inclusion, and the Contested Space of Professionalism within the Legal Market in England and Wales' (2015) 83 Fordham Law Review 2349

${ }^{13}$ Ibid at 2353
} 
committed to public sector service.' ${ }^{14}$ This reification of the market and of business comes at a cost to notions of civic culture and welfarism, and a shift towards a service delivery where cost begins to take precedence over quality, and service of the needs of capitalism takes priority over the needs of the administration of justice. ${ }^{15}$ In this discourse we may well expect a shift in emphasis away from public service aspects of professionalism. Indeed the neoliberalised discourse provides a fertile ground for justification of a market focused approach to legal service provision, freeing lawyers to service the market, rather than serve the public or the public good per se. Whilst commenting on this shift from professionalism to business-led service provision, Webley does however note that much of the Bar has, to date at least, resisted these changes. ${ }^{16}$ It is arguable that the regulatory structure of the Bar has enabled them to do so, and this article will explore whether recent changes to the regulatory regime may be a precedent condition for similar shifts at the Bar.

This article explores two of the main changes introduced to the Bar in the most recent reforms, namely entity regulation, and litigation rights. It is argued that these changes in particular have the potential to allow for a shift in the discourse of professionalism at the Bar towards a more neoliberal discourse and from occupational to organizational form of professionalism. This is a process that has a reasonably long history, but it is the combination of these two changes, and particularly entity regulation, that provide the environment for a different form of professionalism to emerge as dominant.

\footnotetext{
${ }^{14}$ Hilary Sommerlad, 'Managerialism and the Legal Profession: A New Professional Paradigm' (1995) 2(2-3) International Journal of the Legal Profession 159, 181

${ }^{15}$ Hilary Sommerlad, 'The New "Professionalism" in England and Wales' in Spencer Headworth, Robert Nelson, Ronit Dinovitzer, and David B Wilkins (eds), Diversity in Practice: Race, Gender, and Class in Legal and Professional Careers (Cambridge University Press 2016), 228 ${ }^{16}$ Webley (n 12), 2356
} 
Neo-liberal interests can be discerned in some of the underlying justifications for these changes in so far as they give an increased priority to market focussed arguments relating to the promotion of competition, larger units of production and avoidance of economic loss, with a shift in the construct of the professional from craftsman to business person and technician. These changes are in line with a shift to occupational professionalism and may see the profession itself losing some or much of its market control in favour of the promises that come with such a shift of innovation, empowerment and autonomy. These changes may make the Bar more susceptible to movements further in the direction of neoliberalism and deprofessionalisation through stratification, specialisation and a reliance on technicians and technology, with gains in efficiency, but with a consequent shift of focus away from traditionally occupational professionalism to an organizational focus. The next section will consider the changes in the Handbook and the ways in which they introduce greater market theory and occupational professionalism into the way in which contemporary Bar regulation is being constructed.

\section{The Changes: Entity regulation}

The major change introduced through the new handbook is entity regulation. Entity regulation is the terminology commonly adopted in the sector for the shift from regulation of individual lawyers (or partnerships in the case of solicitors) to regulation of corporate providers. These entities may either be lawyer ${ }^{17}$ owned and run, or, more controversially, owned by nonlawyers.

\footnotetext{
${ }^{17}$ Lawyer is used as shorthand here (unless otherwise stated) for the professionals authorised to carry out reserved activities under the Legal Services Act 2007, for example practicing barristers, solicitors or legal executives. It should be noted that the title 'lawyer' is not protected in England and Wales and anyone may offer services under that title.
} 
Traditionally a barrister would choose to either practice as an employed barrister or as a selfemployed barrister. Prior to the recent changes the predominant model of practice at the Bar has been that of the self-employed barrister, and indeed many of the additions to the Bar code of conduct since its creation in 1981 have had the effect of protecting that self-employed status. In that mode of practice the barrister is prohibited from entering into any form of partnership other than the very loose association found in chambers. This generally consists of a formal association whereby members share premises and facilities such as clerking, but are tied to each other's fortunes in no other way: for example, no profit sharing or any form of joint liability. Furthermore barristers were unable when practicing in this way to form companies, so there was also no restriction on that liability. Employed barristers generally had other restrictions and their role was primarily to provide services to their employer, and not to members of the public.

The current trajectory of changes can be traced back to the 1980 and 1990s when the professions' monopolies came under increased scrutiny. Calls for fusion of the professions heightened under the Prime Ministership of Thatcher, and particular under Lord Mackay as Lord Chancellor. Following an increase in legal aid over the preceding decades the Thatcher government began to take action to reduce legal aid and to increase competition in the profession (both of which subsequently continued under the New Labour administration), and the logic of the market began to take hold. As franchising and fixed fees came into operation the competition between solicitor-advocates, with their recently increased rights of audience, and barristers heightened. Employed barristers also gained the ability to advise clients of their employers around this time, and direct access to the bar began to broaden, meaning lay clients 
could instruct barristers without going via a solicitor intermediary. ${ }^{18}$ In 2009 there was a further raft of changes whereby barristers were permitted: to be: managers, employees, and shareholders of Legal Disciplinary Partnerships; to work in dual capacity (i.e. to be both employed and self-employed); to work in partnerships; to share premises; to conduct correspondence; and to attend police stations. ${ }^{19}$

The extent to which these changes have impacted on the work of barristers has largely gone unexamined. ${ }^{20}$ All of these activities had previously been prohibited for the self-employed barrister and had combined to significantly shape their practice and market position. Some of these prohibitions were more restrictive than the better known restriction on the conduct of litigation, which after all only affects matters entering the court system, and has no affect on (for example) advisory work, transactional work or non-court dispute resolution or prevention. Some of the prohibitions produced a dependency on other legal professions (for example prohibitions on attendance at police stations and the conduct of correspondence produce a reliance on solicitors) and others effectively limited the business model of the barrister to that of a sole trader with unlimited liability. Basic innovations of company law and capitalism therefore fell beyond the reach of the barrister (or alternatively the barrister fell beyond the reach of those innovations), who could claim to remain distanced in that way from the commercial world.

\footnotetext{
${ }^{18}$ Richard L Abel, English Lawyers Between Market and State: The Politics of Professionalism (OUP 2004

${ }^{19}$ Ruth Deech, 'How the Legal Services Act 2007 has Affected Regulation of the Bar' (2011) 11 Legal Information Management 89

${ }^{20}$ Although see for example: Atalanta Goulandris, 'Reshaping Professionalism: Branding, Marketing and the New Entrepreneurial Barrister' (2015) 22(3) International Journal of the Legal Profession, 272; and Fernanda Pirie and Justine Rogers (2013) Pupillage: The Shaping of a Professional Elite. In: Abbink J., Salverda T. (eds) The Anthropology of Elites. Palgrave Macmillan, New York
} 
This traditional picture whilst removing barristers from a more sophisticated commercial market can be seen to have positioned them in what might be considered as a fairly classical model of a simple and controlled competitive market where a number of individual units all compete for business in their field in a fairly equal way. This description of course does not factor in issues such as the cultural capital that each unit brings to the market, but this is a weakness when applying simple market models to any field of activity, not just the Bar. Now however, barristers can fall within this more sophisticated market arena and are likely to be subject to new pressures and market forces. They now have the potential to become employees in a broader sense than before, and the full suite of a barrister's potential services become available to a mode of employed practice where they can be fully harnessed to generate profit for entities. The arguments surrounding these changes were persuasively explained within the context of market control theories and non-contractual theories, ${ }^{21}$ however the shift to an organizational focus means that theories based on discourses of professionalism might provide a more suitable framework for analysis of the ongoing effects.

How has the Bar regulator explained this shift and what role does the Bar regulator, the BSB, consider itself to perform in this context? The expressed intention of the BSB is that it will retain a 'niche' status regulating entities which carry out activities similar to the traditional Bar 'which do not hold client money, whose structure is simple and transparent, with work being closely overseen by authorised individuals and minimal risk of divergent interests between owners and managers. ${ }^{22}$ If both rules and policy documents are taken into account the authorisation process does seem to reflect this intention. The authorisation rules themselves are

\footnotetext{
${ }^{21}$ Abel, The Legal Profession (n3); Abel, English Lawyers (n16); Paterson (n 5)

22 Bar Standards Board, 'Entity Regulation Policy Statement', <https://www.barstandardsboard.org.uk/media/1668991/entity_regulation_policy_statement.pdf $>$ accessed 5 January 2018
} 
relatively uninformative in this regard, simply setting up a framework which reflects the Legal Service Act 2007 framework for example requiring a Head of Legal Practice and Head of Finance and Administration, and binding owners and managers to the regulatory arrangements. The one rule that is reflective of the above statement is that which prohibits the holding of client money either directly or indirectly (other than through an appropriately managed third party payment service). ${ }^{23}$ The holding of client money in connection with a legal case has always been the preserve of solicitors in England and Wales.

Authorisation of an entity is a two step process that the BSB addresses through the criteria of eligibility and appropriateness or suitability. Once eligibility is determined under these mandatory rules then the BSB must determine whether the applicant entity is appropriate based on risk assessment, LSA 2007 regulatory objectives and the Entity Regulation Policy of the $\mathrm{BSB}$, and if not appropriate then the BSB may choose not to authorise the entity. ${ }^{24}$ It is the Entity Regulation Policy which gives a clearer indication of what a BSB regulated entity ought to look like and clues about the traits that the BSB considers key to professionalism. The Entity Regulation Policy sets out the discretionary factors used for decision making. The factors are expressed as follows:

'14. The following factors, when present, would tend to indicate that it may be appropriate for the BSB to regulate an entity:

a. all owners and all managers are individuals;

b. $50 \%$ or more of the owners and $50 \%$ or more of the managers are entitled to exercise rights of audience in the Higher Courts;

c. a substantial part of the services to be provided are advocacy and/or litigation services and expert legal advice;

\footnotetext{
${ }^{23}$ Bar Standards Board, Bar Standards Board Handbook (2015), http://www.barstandardsboard.org.uk/media/1720092/bsb_handbook_april_2015.pdf, rS83.5; Hereafter references to rules are to rules from this publication

${ }^{24}$ Rule S99-100
} 
d. the entity is not intending to provide high-volume, standardised legal transactional services;

e. $75 \%$ or more of owners and $75 \%$ or more of managers are authorised individuals;

f. a substantial proportion of employees are going to be authorised individuals; and

g. each manager supervises only a small number of employees.' 25

These factors, along with the rules that apply to entities provide a more complete picture of what an entity will look like, which include the application of the cab-rank rule to regulated entities, which is seemingly employed to distinguish BSB authorised entities from other entities and to make these entities look like traditional barristers. The rule applies to the entities themselves, through a named authorised (BSB or non-BSB) individual, as well as individually to those authorised individuals working in a BSB entity. ${ }^{26}$ Although entity regulation is new, some of the features of the former system of regulation have been retained.

There are also a number of firmer restrictions that have been imported from the self-employed model to the entity model that shape BSB regulated entities in the mould described. BSB authorised bodies, their managers, and barristers employed by them are forbidden from undertaking the management, administration and general conduct of client affairs, nor can they handle client money. ${ }^{27}$ The only context in which barristers can undertake these activities is when they are working from a body authorised by another regulator, for example a body authorised by the Solicitors Regulation Authority (SRA). ${ }^{28}$ Individual lawyers therefore become subject to the regulatory regime that has authorised the entity; barristers employed by

\footnotetext{
${ }^{25}$ Bar Standards Board, Entity Regulation Policy Statement (n 25)

${ }^{26}$ Rule C29; Although on the extent to which the cab rank rule is applied in practice in any case see John Flood and Morten Hviid, 'The Cab Rank Rule: Its Meaning and Purpose in the New Legal Services Market' (January 22, 2013) <https://ssrn.com/abstract=2205124 or http://dx.doi.org/10.2139/ssrn.2205124>

${ }^{27}$ Rules S28-S29 and S31-S34 respectively

${ }^{28}$ Rule S35-S37
} 
an entity authorised under another regulator are freed from some of these restrictions that would have come with being regulated by the BSB if the entity's regulator permits it, and others employed by the BSB regulated entity become restricted by rules heretofore reserved to barristers. Here we see early signs of what a central role entity regulation is to hold for the profession, an indication that the significance of an individual's own professional status is likely to fade in the shadow of the status of the entity, which becomes the more important site of production and regulation.

It can be noted that whilst moving away from a regulation of individuals who have been acculturated into the ethos of 'their' profession, towards entities which may naturally have a more profit driven ethos, the BSB has also expressed a preference for entities that seemingly demonstrate some features that might have been considered part of the trait-based or neocontractual theories of the professions. The favoured traits include: commitment to a ringfenced section of the market (the exercise of rights of audience; advocacy and litigation and prohibitions on conduct of affairs and handling of client money): commitment to high quality expert lead services rather than quantity (the high, albeit unspecified, supervision ratio; high individual authorisation ratio for employees and managers; and discouragement of high volume services): and an (albeit reduced) degree of independence from external influences (the high individual authorisation ratio for owners and managers and the cab rank rule). Here the discourse that has traditionally attached to individual practitioners now attaches to the entity, an emphasis is placed on individual professionals as owners and managers of these entities, and trust and regulation shifts from the individual to the entity.

Only time will tell the extent to which the Entity Regulation Policy factors are rigorously applied, although the initial two cohorts of approved entities suggests that the factors may serve more as an expression of an ideal than as strict criteria, and this too serves to highlight the 
importance of discourse rather than practice here. Apart from the large proportion of single member entities there is already at least one entity (out of just 4 which are not single barrister entities) which, whilst no doubt a perfectly appropriate reserved legal service provider, does not seem to provide a close fit to the specific BSB model described; having no rights of audience itself, being run by individuals who appear to have no rights of audience in the High Court and seemingly focusing on transactional and advisory work. ${ }^{29}$

Whether or not the criteria are rigorously applied, this change, or set of changes, does have the potential to open up avenues for real change in the way that barristers practice, and has more disruptive potential at the Bar than it did for solicitors. This is because the background to which the changes are being applied, as described above, makes it distinct from the equivalent changes for solicitors. When the SRA began regulating new entities it was suggested that this was a change that offered considerable benefits for the larger firms, which for solicitors were already in existence. This was said to be because it would allow growth and diversification through more funding opportunities, allow branding initiatives to operate in new ways, or allowing the realisation of capital through flotation on the stock market. ${ }^{30}$ All barristers however, as described above, were more akin to sole practitioner solicitors, and the predicted benefits of entity regulation, other than any tax related benefits of incorporation are less obvious to these existing practitioners.

Entity regulation therefore shows some retention of the traditional model, but it is unclear at

${ }^{29}$ Bar Standards Board, BSB Entities Register (as at 18/06/2015); https://www.barstandardsboard.org.uk/media/1663530/bsb_entities_register_final_table_for mat_xlsx Accessed 22nd June 2015; Elderflower Legal and Secretarial Services, http://elderflowerlegal.co.uk/ Accessed $3^{\text {rd }}$ August 2015 ${ }^{30}$ Nick Jarrett-Kerr, 'Alternative Business Structures: the Long Pregnancy'(2011) 11(2) Legal Information Management 82 
this stage whether this is based on the competitive advantage of the rhetoric of this model or a public service ethos. Regardless of this, the shift to the larger unit of production without doubt opens up scope for the services of barristers to become profit points for an entity and to therefore become subject to priorities of efficiency. In turn this may result in barristers now becoming forced to act as business people exposed to market pressures and competition, or employees subject to bureaucracy; in either of these cases the nature of the role would be shifting away from traditional models of occupational professionalism towards a more organizational model of professionalism. Here the interests of the BSB are not necessarily aligned to those of the profession itself. If organizational professionalism becomes the dominant discourse (or if it has already done so), then the BSB's shift of focus from individual to entity regulation may position it better in a regulatory marketplace where the regulators themselves are in competition. It therefore seems likely that any resistance to such a shift would need to come from the members of profession itself, possibly coalescing around the Inns of Court.

\section{The Changes: The Scope of Litigation Rights}

As previously indicated, another big change via the Handbook has been the inclusion of the reserved activity of litigation rights for barristers, which has hitherto been the work of solicitors. The BSB has suggested that the introduction of litigation rights, is one of the most significant changes that they have brought in, expressing the view that this 'will do much to help to promote competition in the provision of one-stop advocacy and litigation services. Widening the range of choice available - for the Bar and public too - will bring great benefits to barristers and clients alike. ${ }^{31}$ The themes of competition and consumer choice are therefore

\footnotetext{
${ }^{31}$ Bar Standards Board, Bar Standards Board Annual Report 2013-14 (2014) <https://www.barstandardsboard.org.uk/media/1606527/bsb_annual_report_2013-14.pdf>
} 
strong drivers or justifications for this change, and in this quote they are combined with an implicit invitation to the Bar to step away from traditional models of practice, and perhaps traditional values.

The 2010 Regulating Entities consultation paper considers the main aspects of litigation that were prohibited for barristers to be:

'Issuing any claim or process or application notice, Signing off on a list of disclosure, Instructing expert witnesses on behalf of a lay client, Accepting liability for the payment of expert witnesses, and Any other "formal steps" in the litigation of a sort that are currently required to be taken either by the client personally or by the solicitor on the record.' 32

The latter covers the definition found in statute and case $\operatorname{law}^{33}$ of issuing, commencing, prosecuting or defending proceedings, and the formal steps needed to carry out those activities.

Litigation rights were previously unavailable for self-employed barristers under rule 401(b)(ii) of the old rules, although employed barristers were allowed to conduct litigation provided that they had spent at least 12 weeks working under the supervision of a qualified person. Rule S24.3.b now allows self-employed barristers to conduct litigation if they have obtained an extension to their practicing certificate and they have notified the BSB of their intention to do so. ${ }^{34}$

\footnotetext{
${ }^{32}$ Bar Standards Board, Regulating Entities, (Dec 2010) <https://www.barstandardsboard.org.uk/media/938873/regulating_entites__consultation_paper_-_151010.pdf>, 24

${ }^{33}$ Legal Services Act 2007, Sch 2 Para 4; Agassi v Robinson (Inspector of Taxes) [2005] EWCA Civ 1507

${ }^{34}$ A strict reading of the rules, taking into account the placement of the rule in the section on selfemployed barristers suggests employed barristers do not need to meet this requirement, however additional guidance published by the BSB states that if not already authorised under the old code of conduct they have to follow the same process (Bar Standards Board, Litigation Authorisation
} 
The criteria for eligibility for a litigation extension could have significant effects on the shape of practice, particularly at the junior end of the bar, but potentially for the Bar as a whole. Eligibility for a litigation extension is dependent upon having relevant administrative systems in place to provide legal services direct to clients and to administer litigation, and having the procedural knowledge to conduct litigation competently. If a barrister is less than three years standing she must also be working from the place of practice of a 'qualified person' who is authorised to exercise litigation rights ${ }^{35}$ and who can provide guidance. ${ }^{36}$ This is similar to the requirement for any practice within three years standing, and the requirements for the 'qualified person' differ only in so far as the qualified person must have litigation rights (but does not appear to need to have had them for a prescribed period. ${ }^{37}$ Guidance published separately by the $\mathrm{BSB}^{38}$ explains that the mechanism for implementing these rules are that the barrister must provide the BSB with information that demonstrates they have the required knowledge. Completion of the BPTC and pupillage within the last three years will satisfy this requirement.

- Guidance for Applicants (2014)

https://www.barstandardsboard.org.uk/media/1564863/litigation_authorisation__guidance_for_applicants.doc)

${ }^{35}$ Rule S22.3

${ }^{36}$ Rule S47

${ }^{37}$ The qualified person in both instances must have been entitled to practice, and have practised as a barrister or person authorised by another approved regulator for at least 6 of the previous 8 years, and for the past two years must have made this her primary occupation. The additional requirement for litigation approval is that the person must themselves have entitlement to conduct litigation, but there is no required period (Rule S22.3.iii). This compares to rights of audience where the qualified person must have had full rights of audience for the past two years (Rule S22.2.ii)

${ }^{38}$ BSB, Litigation Authorisation (n 34) 
This means that once a chambers or entity has one experienced ${ }^{39}$ member with litigation rights and a system to deal with litigation (as they must if that experienced member has such rights), then any newly qualified barristers (unless they take a break of more than a year following the BTPC) will be eligible for a litigation extension upon completion of pupillage..$^{40}$ These allows for exponential growth in full service litigation services to the public provided by BSB regulated entities.

The potential snowball effect of one or more members of any chambers obtaining authorisation is therefore not insignificant. This in itself has the potential to change the nature of early practice, with each barrister of over six years call being able to oversee three newly qualified barristers. There is potential here for the newly qualified barrister being persuaded to carry out more routine aspects of litigation, particularly in entities or in chambers where direct access becomes the norm. In doing so they face a potential risk to their own career development both in terms of building advocacy skills and building a solicitor client base. This in turn has the potential for segmentation of the Bar across longitude or cross section. In the former we could have an extended period of development where junior barristers spend longer under the patronage of their seniors, to whom they would remain useful as litigation assistants, almost akin to paralegals, before they eventually escape this neotenous phase and gain the opportunities to develop their broader skills. In the latter there is the possibility of some barristers remaining in this supportive role and the development of a less prestigious career track.

It is interesting to note that there is a minimisation of the practical scope of the litigation

\footnotetext{
${ }^{39}$ Defined in Rule S22.3 as a barrister or other authorised person who has practiced for the last 2 years and at least 6 of the last 8 years, who is authorised to conduct litigation, and is not acting as a qualified person for more than two other people.

${ }^{40} \mathrm{~A}$ barrister can only act as a qualified person for three other barristers at a time.
} 
restriction in the Regulating Entities consultation paper. In making the case that the restrictions on litigation are relatively narrow the paper points to the main restrictions being that a barrister cannot issue proceedings and cannot go on record as the person in charge of the ligitation. The consultation paper goes on to say that 'The effect of this is that a self-employed barrister can handle all of the correspondence in a case, collect evidence and handle the advocacy... However, they would require a solicitor to bridge the gap and actually issue proceedings or take other formal steps. ${ }^{41}$ This is arguably a very narrow and formalistic interpretation of the impact of these restrictions, and their real importance is that they require there to be some division of labour (and income). With such division being imposed it would be rare indeed for the solicitor to accept such a restricted role in a case, as the gap bridging role suggested, and the traditional restriction is likely to have been acting so as to give solicitors first refusal on much of the correspondence and evidence gathering described in that quote which would rarely be passed on to the barrister. Removing the monopoly on the gatekeeping role therefore has wider implications than those described in the consultation, and is likely to move the two branches of the professions to a more common, freer market.

It is however unclear what the take up of litigation rights will be. As already mentioned, the corresponding introduction of Higher Rights of Audience for solicitors did not have the dramatic uptake that was expected or feared in some quarters. As at the 17th June 2015 (i.e. six months after they became available) 45 self-employed barristers had been authorised. ${ }^{42}$ The Barristers' Working Lives survey ${ }^{43}$ found that $14 \%$ of barristers were planning to undertake

${ }^{41}$ BSB Regulating Entities (n 32), 25

${ }^{42}$ Bar Standards Board, 'Barristers Authorised by the BSB to conduct litigation' (June 2014) <https://www.barstandardsboard.org.uk/media/1597601/barristers_authorised_by the_bsb_to conduct litigation - june_2014.xIsx > Accessed 6.9.14

${ }^{43}$ Bar Standards Board and Bar Council, Barristers' Working Lives (2013) <https://www.barstandardsboard.org.uk/media/1597662/biennial_survey_report_2013.pdf> 
litigation (with an additional $26 \%$ saying they 'may' do so). This was most common amongst criminal and family barristers. These are the same sectors that expressed dissatisfaction with life at the Bar with $32 \%$ and $26 \%$ respectively saying that they planned to leave the profession. Therefore, it is possible that the expressed intention to take up litigation rights may reflect a more general dissatisfaction with current practice in those areas rather than a focussed plan to develop an alternative model of delivery. The make-up of public access work (taking instructions from the public directly rather than via a solicitor) is also quite low, $77 \%$ of barristers undertake no public access work, and only $14 \%$ receive more than five percent of their income from public access work. ${ }^{44}$ This could be because litigation restrictions have heretofore had a chilling effect on this work and as the potential arising from the combined liberalisations of these tasks becomes apparent, it may be that more barristers consider them to be attractive options. Interaction with the new opportunities of entity-based practice may also increase uptake and indeed, employers of barristers in entities may ultimately be the ones deciding on these issues with priorities which differ from those of self-employed barristers and which may take more notice of market pressures.

\section{The Changes: The Justification for Litigation Rights}

Litigation rights have long been a strong point of distinction between the two major branches of the legal profession and their availability to barristers is a very recent turnaround. Arguably, this turnaround has come about to facilitate other changes (mainly the move to entity regulation) and to promote competition. In the 'The Structure of Self Employed Practice'45 consultation in August 2009 the BSB dealt swiftly with proposed litigation rights by saying:

\footnotetext{
${ }^{44}$ Ibid

${ }^{45}$ Bar Standards Board, The Structure of Self-employed Practice: Consultation Paper (Aug 2009) < https://www.barstandardsboard.org.uk/media/1390774/structure_self-employed_bar.pdf >, 4
} 
'Other considerations apart, the Board has no reason to believe that there is any significant demand that self-employed barristers should be permitted to engage in such work; and if they were so permitted there would be far-reaching implications for their training and regulation.'

Just over a year later in September 2010 in the Regulating Entities consultation there had been a change and the position was that if $\mathrm{BSB}$ regulated entities should be able to conduct litigation, then so too should self-employed barristers. It is perhaps telling that when the context of the decision shifted from self-employed practice to entity regulation the direction of the decision changed, and this is an area where it appears fairly clear that the motivation for the change is based on the model of the entity rather than the individual practitioner, and a reorientation of the BSB's conception of its regulatory role.

In the latter Regulating Entities consultation the BSB considered the benefits of litigation rights to be consumer choice and competition. Consumer choice was seen to be enhanced by avoiding the extra expense of instructing a solicitor, following the Office of Fair Trading's view on this point. ${ }^{46}$ It listed other benefits but these related to entities having litigation rights, and a major tenet of the approach to litigation rights for self-employed barristers seems to be harmonisation of what individual barristers can do with what entities can do. Disadvantages were acknowledged to be the extension beyond the Bar's traditional remit and traditional skills base, loss of specialism (seen as reducing the quality of service for the client), and increased overheads. A further risk was seen to be convergence between barristers' and solicitors' professions. This was seen to have the potential to be contrary to the regulatory objective of 'encouraging an independent, strong, diverse and effective legal profession' 47 and contrary to

\footnotetext{
${ }^{46}$ Office of Fair Trading, 2001, Competition in the Professions - A Report by the Director General of Fair Trading

${ }^{47}$ Legal Services Act 2007 s1(f), although note the use of the singular form of 'profession'
} 
the wishes of $88 \%$ of barristers. The BSB argued that a distinction would still persist in that barristers would remain prohibited from undertaking general conduct of a client's affairs, and therefore from acting on a retainer as general counsel for any particular client. ${ }^{48}$ Specifically in relation to self-employed barristers it cited its own survey result that $52 \%$ of barristers felt that self-employed barristers should be able to engage in litigation, but against that it recognised the risk that the demands of an advocacy based practice could impinge on proper management of litigation. ${ }^{49}$

The advantages offered by the consultation paper seem weak when considered in context. The promise of lower consumer costs is diluted by the paper's admission that overheads would increase; and secondly an increase in competitiveness or consumer choice must be balanced against a potential drop in quality from loss of specialisation and conflicting obligations. However, where a traditional professional concern (specialisation, expertise, conflict of duties, quality) came up against a more neoliberal value (competitiveness, market choice), the BSB gave priority to the latter. Market liberalisation (as between branches of the profession) and an increase in consumer choice prevailed.

Where the profession raised concerns over fusion between the solicitor and barrister branches of the legal profession the BSB drew direct comparisons with the awarding of higher court rights to solicitors, which had not had as high take-up as anticipated. It also pointed to the areas where the Bar would not be competing with solicitors, namely conducting client affairs, mass conveyancing (not only reserved to solicitors), and will writing (not reserved to legal professionals at all in England and Wales).

\footnotetext{
${ }^{48}$ BSB Regulating Entities (n 32), 27-33

${ }^{49}$ Ibid, 27-33
} 
'The role of solicitors and barristers will therefore remain in many respect distinct even though there will be some increase in the range of work they can both do and in the area of overlap. ${ }^{50}$

Responses to the consultation highlighted concerns about the corresponding reduction in expertise, which ran contrary to the public interest. The BSB countered this argument with reference to practice in other jurisdictions, and by citing the quality assurance measures such as the Quality Assurance Scheme for Advocates. Consultation responses also raised concerns about the risk that newly qualified barristers may be given administrative litigation tasks, lessening their chance to develop their advocacy skills. Again the BSB relied upon a somewhat vague comparison with 'other jurisdictions'. As discussed above, the authorisation process increases this risk.

There was a dismissal of both concerns of lack of specific professional identity and worries about the deskilling at the junior end of the bar. Loss of identity seems to be a major concern both in the consultation document and in the responses, including a slide into a hybrid of generalist approach to the different branches and role of the profession with a particularly negative impact on junior barristers who might be pressured into 'performing roles equivalent to those of solicitors. ${ }^{51}$ The BSB had initially proposed that any litigation service must be ancillary to advocacy services, which would have guarded against these concerns to some degree, and the Access to the Bar Committee also proposed a similar rule. The BSB ultimately decided against this on the basis that it would be impractical to define any such rule but also because the restrictions on handling client money would make it unlikely that litigation would

\footnotetext{
${ }^{50}$ Bar Standards Board, Regulating Entities Consultation Report (May 2011) < https://www.barstandardsboard.org.uk/media/938893/regulating_entities__consultation_report_may_2011.pdf >, 18

${ }^{51}$ Ibid, 22
} 
be exercised except as ancillary to advocacy in any case. The BSB drew attention to what it perceived to be the benefits to the public of BSB regulated entities being able to perform a wider range of services and lack of 'an identifiable public interest reason' to maintain the restriction. This assertion is somewhat curious in light of the paper's identification of risks of increased overheads (and therefore presumably increased cost to the client), lowering of quality through reduced specialisation and expertise, loss of distinct identity and difficulties managing conflicting obligations. The concerns from 2009 of 'far reaching implications for training and regulation' 52 appear to have been assuaged by the introduction of a self-assessment questionnaire for barristers who are not required to have any specific training to undertake this work.

It is an unavoidable conclusion that the BSB was either overstating the implications of introducing litigation rights in 2009 or has been downplaying them since 2010 . No empirical research appears to have been carried out in the interim, other than the consultation in which the BSB had already made a provisional decision to allow litigation from the outset, although the consultation paper quotes a lengthy paragraph from a letter from the Office of Fair Trading to the Legal Services Board in which there is an emphasis on cost savings. ${ }^{53}$ Here then a set of concerns centring on individual professional identity, distinctiveness and quality, all features of a neo-contractual approach are largely dismissed in favour of an approach which would open up the market and provide a suitable environment for entities to operate successfully. This suggests that the BSB is shifting closer towards an organisational regulatory model, eschewing its more traditional functionalist approach.

The relatively sudden volte-face to favour litigation rights therefore starts to disclose an

\footnotetext{
${ }^{52}$ BSB Structure of Self Employed Practice (n 45), 4

${ }^{53}$ BSB Regulating Entities (n 32), 27
} 
increasingly market based orientation for change, with a sweeping away of old concerns that were more tied up in traditional notions of professionalism of professional duty, distinctiveness of identity, and specialisation. This is accompanied by a light touch licencing procedure that has scope to contribute to stratification of the profession in less clear cut ways than the preexisting distinctions between barrister and solicitor. Again we see the BSB tailoring its regulatory regime to the needs of entities. This is particularly apparent in the reversal of position on litigation rights once entity regulation entered the field.

\section{Discussion}

In the BSB's approach to entity regulation we see the diminishing importance of individual professional status as the status of the entity rises. As barristers become sources of profit within these entities it seems likely that the logic of the market will both facilitate, and be given increasing importance by, a corresponding shift to the discourse of organizational professionalism at the Bar. Whilst there is some ambiguity as to the motivation of the BSB in matching the values of entities to the values associated with individual professionalism, the motivation in the case of litigation rights seems far more clearly related to the needs of entities and makes this ambiguity seem far more likely to represent a recognition of the value of the discourse of professionalism. This clarity is revealed by the complete turn around in explicitly stated positions on litigation rights once the needs of the entity are recognised and supported by a repeated favouring of neoliberal values over traditional neo-contractual traits of occupational professionalism.

These changes in the rules lead to potential changes in the working practices of the Bar, which make the shift to organizational professionalism more likely. The transparency that entities bring to the working practices of the barristers working within them allows 
technological advances, in terms of both regulatory technology 54 and information technology to accelerate and maximise the productivity and profitability of entities who wish to take advantage of these.

Barristers have to date operated in a highly traditional mode, somewhat sheltered from external forces by restrictions placed upon them. Prior to the changes described, the nature of the restrictions on barristers working together meant that they had not begun developing partnership models in the same way that solicitors had been able to. This preserved a very bespoke and somewhat idiosyncratic way of working that makes the analogy $\operatorname{Kritzer}^{55}$ used to analyse the decline of the professions particularly salient.

Kritzer compared the decline of professions to the decline of craftsmen through the industrialisation process of the nineteenth century and described post-professionalism as being driven by loss of exclusivity, increased segmentation and specialisation, and increases in technological solutions. In these conditions a process of bureaucratization leads to a loss of control of the production by producers described by Abel. ${ }^{56}$ Kritzer ties this to the rationalisation of professional knowledge and professional tasks, and of particular relevance notes the tendency to break down complex processes into their component parts that, developing the analogy, when combined with technological advances allowed craftsmen to be replaced by factory workers. Whilst this process acted upon the production of physical products in that setting, in the professional setting we see a similar process acting upon the production of knowledge based products. Barristers, in their model of lone working, and responsibility for

\footnotetext{
${ }^{54}$ Including regulatory changes pre-dating entity regulation, such as direct access, which may now be seen to have new potential.

${ }^{55}$ Herbert M Kritzer, 'The Professions are Dead, Long Live the Professions: Legal Practice in a Postprofessional World' (1999) 33(3) Law \& Society Review 713

56 Abel, The Legal Profession (n 3)
} 
an entire product once instructed, perhaps now typify the craftsman more than any other branch of the legal profession, and are in their predominant mode of practice the least bureaucratized legal profession. The restriction against working in any form of corporate structure, including even partnership, no doubt leads to the retention of this mode of production preventing the barrister from easily breaking down her production process into delegable tasks.

The advent of the entity has the potential to expose barristers' working practices to new profit focussed actors, and in doing so to change the nature of those practices. Under the model of lone working any benefit derived from technical assistance would be realised by the sole practitioner, but would be invisible to any other observer or process. The barrister is in many ways a 'black box' where instructions go in and product comes out, with any processes taking place within the box being largely irrelevant and possibly invisible to the rest of the world. Whilst delegation to others has therefore remained difficult or impossible, delegation to technology remained unseen and hidden. However, the advent of the entity has the potential to make working with others possible, and to make any delegation to technology visible. The first of these is an obvious outcome of entity regulation and leads to the latter. As barristers begin working with others (even other barristers) in corporate structures their practices become a matter of concern for those corporate structures, and there working practices fall more in line with an organizational form of professionalism.

Where efficiency becomes a key driver then technological delegation shifts from being a time saver to being a cost saver as the individual barrister's time becomes a human resource of the entity with an associated cost. This then places technology as part of a picture where processes can become rationalised and certain tasks in the process require only a narrow skill set. This allows for tasks to be delegated to the cheapest producer, be that a barrister, a pupil, a solicitor, 
a legal executive, a paralegal or an algorithm. Whilst Goulandris, ${ }^{57}$ after examining the development of active marketing at the Bar, concludes that the changes 'do not appear to have undermined core professional values of individual autonomy, expertise or collegiality', those changes were introduced long before entity regulation and for the reasons described above this more recent change has far greater disruptive potential.

The extent to which the professionals themselves, the barristers, assimilate into or resist this new mode of professionalism will of course only become apparent in time. As noted by Boon, ${ }^{58}$ the narrative of the barristers' profession has historically been more related to liberalisation in the political and legal spheres as compared to the 'solicitors' narrative [which] is aligned with economic liberalisation and the evolution of a capitalist economy.' ${ }^{59}$ Arguably this may make barristers more likely to resist (or alternatively, less likely to embrace) market focused changes. It should be noted however that there are some indications of sections of the Bar being willing to embrace the drive towards increased commerciality, for example through the increased use of practice managers or pro-active senior clerks overseeing multiple levels of management and having significant input into business development. ${ }^{60}$ There is also the possibility that even a small degree of assimilation will remove strategies to resist these changes by taking the decisions about the working lives of barristers away from the barristers themselves, and into the hands of those controlling the entities (who may be barristers too, but are likely to be a smaller, more elite, group). As Sommerlad has pointed out 'As soon as it is conceded that professional knowledge and expertise may be subjected to analysis in terms of its component

\footnotetext{
57 Goulandris (n 20), 295

${ }^{58}$ Andrew Boon, 'The Legal Professions' New Handbooks: Narratives, Standards and Values' (2016) 19(2) Legal Ethics 207

${ }^{59}$ Ibid

${ }^{60}$ Goulandris (n 20), 272
} 
skills, then that professional knowledge and expertise no longer belongs entirely to either the profession or the individual [lawyer] but inheres in procedures and machines.' 61

On the one hand the opening up of the playing field may drive barristers into entities which eventually but inexorably lead to the rationalisation, segmentation and deprofessionalisation of much of their work. On other hand the pattern the initial uptake, if maintained (and it is worth considering that this may be the pattern precisely because it is the initial uptake), suggests that barristers may successfully resist this by subversively using the innovative regime to stay exactly where they are (only in a potentially more tax efficient way). It may be that the outcome lies in hands that have never touched the dining tables of any Inn, and that the uptake of BSB entity status by individuals authorised by other regulators will leave individual barristers with no choice other than to compete with these advocacy and litigation focussed entities by producing new models of their own. The introduction of entity regulation appears to be a tipping point that makes it likely that the discourse of organizational professionalism will come to take precedence over occupational forms at the Bar. The recent regulatory strategy of the BSB has shifted in ways that improve their position to operate within this environment, with an increased focus of the needs of entities. This is made apparent not just through the framework for entity regulation but also through development of rules in other areas, which focus on the needs of entities, as shown through the example of litigation rights. It allows the BSB better to operate in a market of legal regulators, to provide a tailored solution to all who wish to specialise in providing litigation and advocacy services to the public or via solicitors. It carves out a delineated market for itself and in doing so brings a range of legal professionals (and others) within its scope.

\footnotetext{
${ }^{61}$ Sommerlad, Managerialism and the Legal Profession (n 15), 182
} 
